(c) American Dairy Science Association, 2006.

\title{
Eating Rate and Preference of Different Concentrate Components for Cattle
}

\author{
E. Spörndly ${ }^{1}$ and T. Åsberg \\ Swedish University of Agricultural Sciences (SLU), Department of Animal Nutrition and Management, \\ Kungsängen Research Center, SE-753 23 Uppsala, Sweden
}

\begin{abstract}
Different feeds or combination of feeds were studied in 11 short-term experiments with the objective to identify concentrates that were especially desirable for cattle. Eating rate of different feeds was studied in 6 experiments using 10 heifers in a Latin square design with 2 blocks of 5 animals, 5 treatments (feeds), and 5 periods (days). Preference as shown by feed choice was studied in 5 experiments with 12 heifers. Paired comparisons of 4 different feeds ( 1 through 4 ) in the 6 possible combinations of 1 and 2,1 and 3, 1 and 4, 2 and 3, 2 and 4, and 3 and 4 were performed. A control feed of ground barley was included in all experiments. In the eating rate and preference experiments, a total of 25 and 16 feeds, respectively, were studied. The categories of feeds studied were basic feeds, such as cereals, soybean meal, and rapeseed products, and feed mixtures based on ground barley with sweet additives or additives based on fat products. Pelleted concentrate mixtures were also evaluated. From the results obtained, the following feeds were identified as being among the most preferred feeds: pelleted feeds, heat-treated rapeseed meal, barley with $10 \%$ rapeseed fatty acid, barley with $10 \%$ palm oil, and barley with $10 \%$ glycerol, whereas ground palm kernel expeller was undesirable. A clear preference for pellets over ground barley was demonstrated, but no difference in preference was observed for the 3 different pellets that were compared.
\end{abstract}

Key words: concentrate, preference, eating rate, cattle

\section{INTRODUCTION}

The use of small amounts of palatable feed to entice animals to come or to move in a specific direction has always been used in different management situations. For cattle, the use of concentrate for this purpose has

Received June 1, 2005.

Accepted January 12, 2006.

${ }^{1}$ Corresponding author: Eva.Sporndly@huv.slu.se become more common with the introduction of automatic milking. In automatic milking systems (AMS), cows are expected to voluntarily go to the milking unit several times daily to be milked. This can be a problem to overcome, especially during the grazing season (van Dooren et al., 2002) and when the grazing area is not situated close to the barn (Spörndly and Wredle, 2004). In experiments conducted by Rodenburg et al. (2004), a number of different concentrate mixtures were compared with the objective of finding a palatable concentrate to use in AMS, but none of the experimental diets proved more palatable than commercial concentrate pellets that acted as the control diet. In AMS there are several alternatives for concentrate feeding. In some systems only small amounts of concentrates are given in the milking unit whereas the major portion of the concentrate ration is fed in separate concentrate feeders (Melin et al., 2005). This management practice has been adopted with the motive to minimize the time cows spend in the milking unit and to ensure sufficient time for concentrate intake for the high-yielding cow. The present study was initiated with the aim of finding concentrate components that were especially desirable and suitable to feed in small amounts in the milking unit in AMS to entice cows to visit the milking unit regularly. The small concentrate ration made it possible to study feed components or mixtures in which the nutrient content did not need to be to be optimized. The objective of the large number of short-term experiments performed in this project was to screen numerous feeds to identify the ones most desired by cattle. In the first 6 experiments, eating rate was used as an indirect measurement of feed desirability and in the following 5 preference experiments, animals were offered different choices of feed, in part using the same feeds as in the first 6 experiments where eating rate was measured.

\section{MATERIALS AND METHODS}

\section{Animals, Feeding Routines, Experimental Design, and Concentrate Components}

Experiments 1 to 6: Eating Rate. Eating rate of different concentrate components was studied with 10 
dairy heifers of the Swedish Red and White breed in 6 short-term experiments with a Latin square design in which heifers were randomly allocated to treatment sequence. Experiments 1 to 5 were performed in succession, with only 1 or $2 \mathrm{~d}$ between experiments, and Exp. 6 was performed a few months later with a different group of animals. Heifers in Exp. 1 to 5 had an average live weight of $545 \mathrm{~kg}$ (range 484 to $654 \mathrm{~kg}$ ) and an average of $101 \mathrm{~d}$ to calving (range 38 to $140 \mathrm{~d}$ ) at the initiation of Exp. 1, and heifers in Exp. 6 had an average live weight of $551 \mathrm{~kg}$ (range 492 to $585 \mathrm{~kg}$ ) and an average of $92 \mathrm{~d}$ to calving (range 66 to $133 \mathrm{~d}$ ) at the start of the experiment. Each of the 6 experiments comprised 2 blocks of 5 heifers, 5 treatments, and 5 one-day periods including 1 morning and 1 afternoon feeding. All heifers were reared on roughage (mainly silage, pasture, and occasionally hay and straw) during the last 18 mo before initiating the experiments and, thus, heifers had limited experience of regular concentrate feeding. The concentrates were fed twice daily at 0800 and $1400 \mathrm{~h}$. On each feeding occasion, animals were presented with exactly $1 \mathrm{~kg}$ of a concentrate component, and the time it took for the animal to consume the feed offered was registered with a stopwatch. After $3 \mathrm{~min}$, the meal was interrupted and the feed was weighed to obtain an eating rate for the first part of the meal. This procedure was quick and took less than $30 \mathrm{~s}$, whereupon the stopwatch was restarted and the remainder of the concentrate meal was given to the animal to consume. After the feed was consumed, the total time for the entire meal was registered. Small amounts of feed (up to $50 \mathrm{~g}$ ) left in the corners and on the sides of the feed trough when the meal was completed were weighed and registered. Feed remaining after 10 min was removed, weighed, and registered, and the eating rate was based on the amount consumed within the 10-min period. Eating rate was calculated as grams of consumed feed per minute. The changes in eating rate and in amounts of feed leftovers between the morning and afternoon feedings were also calculated. A higher eating rate at the afternoon meal compared with the morning meal was an indication of a positive reaction to the new feed, and conversely, a decrease in eating rate from morning to afternoon feeding and an increase in amounts of leftover feed was seen as a negative reaction.

The animals were fed individually. Before offering a heifer her concentrate meal, the adjacent heifer was enticed with $1 \mathrm{~kg}$ of straw to avoid disturbing the animal being registered. Beside treatment feed (concentrate components) and some straw, the animals were fed $5 \mathrm{~kg}$ of DM silage/animal per d. Dry matter content of grass silage was $33.7 \%, \mathrm{CP}$ and $\mathrm{NDF}$ content was
14.3 and $47.6 \%$ of DM, respectively, and energy content was $11.0 \mathrm{MJ}$ of $\mathrm{ME} / \mathrm{kg}$ of DM. The daily ration of silage was given 3 times daily at 0600,1200 , and 1700 h. Roughages were fed in the morning and at noon at approximately $2 \mathrm{~h}$ before the feeding of concentrate components. To ensure that the routines and judgment of when the meal was consumed were uniform, the same person timed the length of the meals, with the exception of 3 occasions. Exp. 1 to 5 were performed in succession with 1 or 2 nonexperimental days between the experiments. During these intermediate days, heifers were given $1 \mathrm{~kg}$ of ground barley (GB) control feed twice daily.

To minimize the effects of differences in feed structure in Exp. 2 to 6, the feed components with a large particle size, i.e., barley as control feed (Exp. 2 to 6) and barley in mixtures (Exp. 3, 4 and 5), alfalfa, oats, wheat, heat-treated rapeseed meal (HT-RSM), and rapeseed expeller (RSE), and peas were ground in a hammer mill with a 3-mm screen to standardize particle sizes. Experiment 1, however, was performed with feeds as they are sold to the farmers and, therefore, the structure of the feed components differed. Experiment 6 was performed as a follow-up, with 3 of the same feed components as in experiment 1, ground to obtain a comparable structure. Analysis of particle size of the different feed components was performed using a number of screens with different pore sizes $(4,2.8$, $2,1.4,1,0.7,0.5,0.355,0.25,0.18$, and $0.125 \mathrm{~mm}$ ). Only a small portion of the particles, in most cases 0 to $1 \%$ of the sample, passed through the last screen, and these particles were assumed to have the size of $0.06 \mathrm{~mm}$ (half of the final screen pore size). A mean particle size for each feed component was obtained by using the midpoint between the screen sizes and the proportion of the sample remaining on each screen layer. The concentrate components studied in Exp. 1 to 6 are presented in Table 1, together with the abbreviations used for the different concentrates.

Barley and sweet additives were weighed and mixed to obtain a sugar content of $15 \%$ in the mixture using table values (Spörndly, 2003) for the content of sugar and DM in the feed components. The proportion of the sweet additives varied depending on the sugar content of the product (see footnotes to Table 1).

The commercial fat products (Fats 1 and 2) were solid flakes or small round pellets and mixing presented no problem, and the liquid products such as oils, fatty acids, and molasses were poured and mixed simultaneously into the GB. The solid fat products of coconut and palm tree origin were carefully warmed to a liquid state before mixing.

Experiments 7 to 11: Preference. In 5 different feeding trials, preferences for different concentrate 
Table 1. Treatments (concentrates) in Experiments 1 to 6 and abbreviations used for the feeds that were studied ${ }^{1,2}$

\begin{tabular}{|c|c|c|c|c|c|}
\hline & Feed 1 & Feed 2 & Feed 3 & Feed 4 & $\begin{array}{l}\text { Feed } 5 \\
\text { (control }\end{array}$ \\
\hline Exp. 1: Protein feeds 1 & HT-RSM & RSM & SBM & Ground alfalfa & GB \\
\hline Exp. 2: Carbohydrate feeds & Ground wheat & Wheat bran & Ground oats & Palm kernel expeller & GB \\
\hline Exp. 4: Barley + fat products ${ }^{4}$ & $\mathrm{~GB}+\mathrm{CNFA}$ & $\mathrm{GB}+\mathrm{CNO}$ & $\mathrm{GB}+\mathrm{RSFA}$ & $\mathrm{GB}+\mathrm{RSO}$ & GB \\
\hline Exp. 5: Barley + fat products ${ }^{4}$ & $\mathrm{~GB}+\mathrm{PFA}$ & $\mathrm{GB}+\mathrm{PO}$ & $\mathrm{GB}+$ Fat1 & GB + Fat2 & GB \\
\hline Exp. 6: Protein feeds 2 & Ground HT-RSM & Ground RSE & SBM & Ground peas & GB \\
\hline
\end{tabular}

${ }^{1}$ Several feed components with large particle size in Exp. 2 to 6 were ground to obtain comparable structure. Ground barley acted as a control feed in all the experiments and was used as a base in mixtures with sweet additives and additives based on fat products. Rapeseed products were of the double-low type; i.e., low in erucic acid and glycosinolates.

${ }^{2} \mathrm{~GB}=$ Ground barley; HT-RSM = heat-treated rapeseed meal ('Expro'; www.karlshamns.se); RSM = rapeseed meal; SBM = soybean meal; $\mathrm{M}=$ molasses ( $30 \%$ of feed); $\mathrm{SBP}=$ ground sugarbeet pulp ( $65 \%$ of feed); $\mathrm{SU}=$ sugar $(13 \%$ of feed $) ; \mathrm{WH}=$ whey powder $(19 \%$ of feed $) ; \mathrm{CNFA}=$ coconut fatty acid; $\mathrm{CNO}=$ coconut oil; RSFA = rapeseed fatty acid; RSO = rapeseed oil; PFA = palm fatty acid; PO = palm oil; Fat 1 = fat product 'Akofeed Cattle'; Fat 2 = fat product 'Akofeed Gigant' (www.karlshamns.se); RSE = rapeseed expeller.

${ }^{3}$ Added to obtain $15 \%$ sugar in the feed product.

${ }^{4}$ Added to obtain $10 \%$ fat product in the feed.

components were studied with 12 dairy heifers of the Swedish Red and White breed. The heifers had an average live weight of $493 \mathrm{~kg}$ at the start of the experiment (range 455 to $531 \mathrm{~kg}$ ), and on average were 117 $\mathrm{d}$ to calving (range 91 to $143 \mathrm{~d}$ ). In each feeding trial 4 concentrate components were studied, and the heifers were offered a choice between 2 of the 4 concentrate components daily. Ground barley was included in all of the trials and acted as a control feed. The 4 different feed components (1, 2, 3, and 4 ) form 6 possible pairs ( 1 and 2,1 and 3,1 and 4,2 and 3,2 and 4, and 3 and 4). To obtain a balanced design, the pairs were regarded as treatments and a Latin square design with 2 blocks of 6 heifers, 6 periods, and 6 treatments (consisting of a choice between 2 concentrates) was used. The animals were randomly allocated to treatment sequence and each period lasted $1 \mathrm{~d}$, in which the animals were offered a choice between 2 concentrate components twice daily at the morning and afternoon feedings. To avoid possible lateral preference effects, the position of the 2 feeds was alternated so that the feed offered to the right in the morning was offered to the left in the afternoon and vice versa. Feeding took place from 0800 to $1000 \mathrm{~h}$ and from 1400 to $1600 \mathrm{~h}$. The concentrates were fed manually to the individual animal. Two feed containers were placed in front of each heifer to ensure separation of the experimental feeds. At feeding, $0.5 \mathrm{~kg}$ of each of the 2 concentrates was given simultaneously in the feeders and timed with a stopwatch. The time spent eating each of the 2 feeds was registered in a protocol noting sequence of feed choice and the time on each occasion when the animal switched from one concentrate to the other. If the 2 feeds were not consumed after $10 \mathrm{~min}$, the leftovers were removed, weighed, and registered. At each feeding occasion, the concentrate that the heifer preferred - the winner ( $\mathbf{W})$ - and the less attractive feedthe loser ( $\mathbf{L})$-were identified using the following criteria ranked in order of importance: 1 ) the first concentrate was completely consumed (W) before the second (L); 2) the animal smelled or tasted the one concentrate for at most $20 \mathrm{~s}(\mathrm{~L})$ but switched to the second concentrate $(\mathrm{W})$ and ate for at least $1 \mathrm{~min}$ or more; and 3) the first concentrate (W) that was consumed during a time interval of $30 \mathrm{~s}$ or more without the animal switching to the second concentrate. If a winning feed could not be clearly identified using the first criterion, the second was tested, and if neither of these criteria were met, the third criterion was used to identify the winning feed. If the animal chose the same feed both at the morning and afternoon feeding, this feed was registered as preferred before the other. However, if the choice differed on the 2 feeding occasions, the result was registered as "no preference".

Before offering a heifer her concentrate meal, the adjacent heifer was offered straw to occupy the animal and avoid disturbing the heifer being registered. Apart from concentrates and straw, heifers were fed $5 \mathrm{~kg}$ of DM grass silage daily with a DM content of $35.3 \%$, a $\mathrm{CP}$ and NDF content of 17.9 and $45.2 \%$ of DM, respectively, and an energy content of $11.8 \mathrm{MJ}$ of ME per kg of DM. The silage ration was divided into equal portions that were fed at 0600 and $1200 \mathrm{~h}$ (i.e., $2 \mathrm{~h}$ before concentrate feeding) and at $1800 \mathrm{~h}$. The experiments were performed in a sequence with 1 or $2 \mathrm{~d}$ between the end of 1 experiment and the start of the next. During these intermediate days, the animals received the control feed (GB) given in same amounts at the same times as during the earlier experiments. The heifers included in Exp. 7 to 11 were reared on rough- 
Table 2. Concentrates compared in preference Experiments 7 to 11 and abbreviations used for the feeds that were studied ${ }^{1,2}$

\begin{tabular}{|c|c|c|c|c|}
\hline & Feed 1 & Feed 2 & Feed 3 & $\begin{array}{l}\text { Feed } 4 \\
\text { (control) }\end{array}$ \\
\hline Exp. 7: Protein feeds & HT-RSM & HT-RSM + RSFA & SBM & GB \\
\hline Exp. 8: Barley + sweet additives ${ }^{3}$ & $\mathrm{~GB}+\mathrm{M}$ & $\mathrm{GB}+\mathrm{SBP}$ & $\mathrm{GB}+\mathrm{SU}$ & GB \\
\hline Exp. 9: Barley + fat products 4 & GB + Gly & GB + Fat2 & $\mathrm{GB}+\mathrm{CaF}$ & GB \\
\hline Exp. 10: Barley + fat products ${ }^{4}$ & $\mathrm{~GB}+\mathrm{RSFA}$ & $\mathrm{GB}+\mathrm{PFA}$ & $\mathrm{GB}+\mathrm{CNFA}$ & GB \\
\hline Exp. 11: Concentrates ${ }^{5}$ & Pellets 1 & Pellets 2 & Pellets 3 & GB \\
\hline
\end{tabular}

\footnotetext{
${ }^{1}$ Ground barley acted as a control feed in all the experiments and was used in mixtures with sweet additives and additives based on fat products. Rapeseed products were of the double-low type; i.e., low in erucic acid and glycosinolates.

${ }^{2} \mathrm{~GB}=$ Ground barley: HT-RSM = heat-treated rapeseed meal ('Expro' www.karlshamns.se); RSFA = rapeseed fatty acid; $\mathrm{SBM}=$ soybean meal; $\mathrm{M}=$ molasses $(30 \%$ of feed); $\mathrm{SBP}=$ ground sugarbeet pulp $(65 \%$ of feed); SU = sugar (13\% of feed); Gly = glycerol; Fat 2 = fat product 'Akofeed Gigant' (www.karlshamns.se); $\mathrm{CaF}$ = calcium soapfat; RSFA = rapeseed fatty acid; PFA = palm fatty acid; CNFA = coconut fatty acid.

${ }^{3}$ Added to obtain $15 \%$ sugar in the feed product.

${ }^{4}$ Added to obtain $10 \%$ fat product in the feed.

${ }^{5}$ Pellet composition listed in Table 3.
}

age (mainly silage, pasture, and occasionally hay and straw) during the 18 mo before initiation of the experiment and had limited experience of regular concentrate feeding. The concentrates studied in Exp. 7 to 11 are presented in Table 2, together with abbreviations used, and include many of the concentrates studied in the eating rate Exp. 1 to 6. As in Exp. 1, the HT-RSM used in Exp. 7 had the same structure as that of the product that was commercially available on the market. The composition of pellets 1 to 3 used in Exp. 11 is listed in Table 3.

\section{Feed Analysis}

The DM of feeds and feed mixtures was obtained by drying for $18 \mathrm{~h}$ at $103^{\circ} \mathrm{C}$; ash content was obtained after heating at $550^{\circ} \mathrm{C}$ for $3.5 \mathrm{~h}$; CP was determined using the Kjeldahl method according to the Nordic

Table 3. Percentage composition of the concentrate pellet mixtures 1, 2, and 3 in Experiment 11

\begin{tabular}{lclc}
\hline & Pellets 1 & Pellets 2 & Pellets 3 \\
\hline Barley & 27 & 37.5 & 29 \\
Oats & 15 & 15 & 14 \\
Sugarbeet pulp & 20 & 20 & 15 \\
Soybean meal & 0 & 13 & 0 \\
Soypass $^{1}$ & 0 & 10 & 0 \\
HT-RSM $^{2}$ & 20 & 0 & 18 \\
Rapeseed cake $_{\text {Dried draff }}$ & 0 & 0 & 12 \\
Peas & 15 & 0 & 0 \\
Rapeseed oil & 0 & 0 & 10 \\
Wheat bran & 3 & 4.5 & 0 \\
\hline
\end{tabular}

\footnotetext{
${ }^{1}$ Borregaard Lignotech, Sarpsborg, Norway.

${ }^{2}$ HT-RSM = Heat-treated rapeseed meal 'Expro' (www.karlshamns.se).

${ }^{3}$ Agrodrank90 (www.agroetanol.se).
}

Committee on Food Analysis (1976); and NDF in silage was analyzed according to Goering and Van Soest (1970). Content of crude fat in the concentrate feeds was determined according to a European Union standard method (European Union, 1984). The contents of fatty acids in the different fat-based products were determined according to the IUPAC description 2.303 (International Union of Pure and Applied Chemistry, 1992). Water-soluble carbohydrates analyses were performed according to Larsson and Bengtsson (1983) to determine the sugar content in the feeds with the sweet additives. For the mixture of ground barley and whey, separate lactose analysis was performed on a water extract after 15 min of ultrasound treatment using an HPLC system equipped with a ReproGel $\mathrm{H}$ column (A. Maisch, Ammerbuch, Germany) at $64^{\circ} \mathrm{C}$ using a refractive index detector, applying the procedure for organic acids as described by Andersson and Hedlund (1983) but calibrated for lactose. The content of ME in the grass silage was determined by in vitro digestion as described by Lindgren (1979). The nutritive contents of the concentrate feeds in Exp. 1 to 11 are listed in Table 4.

The content of fatty acids and the proportion of free fatty acids in the fat products are presented in Table 5 . The content of free fatty acids in coconut fatty acid (CNFA) and in palm fatty acid (PFA) in Exp. 10 was 59.4 and $53.7 \%$, respectively. Apart from this, the additives used in Exp. 10 had a similar fatty acid composition as the fatty acid additives used in Exp. 4 and 5 and are therefore not presented separately in Table 5 .

\section{Statistical Analyses}

Eating rate, amounts of unconsumed feed, differences in eating rate between morning and afternoon 
Table 4. Content of DM, ash, CP, and fat (Experiments 1 to 11) and sugar content (Experiments 3 and 8 ) in studied feed components ${ }^{1}$

\begin{tabular}{|c|c|c|c|c|c|}
\hline & \multirow[b]{2}{*}{ DM \% } & \multicolumn{4}{|c|}{$\%$ of $\mathrm{DM}$} \\
\hline & & Ash & $\mathrm{CP}$ & Sugar & Fat \\
\hline \multicolumn{6}{|l|}{ Experiments 1 to 6} \\
\hline GB (Control) & 89.6 & 2.9 & 15.4 & 2.0 & 1.6 \\
\hline HT-RSM & 91.4 & 8.1 & 37.0 & - & 4.1 \\
\hline RSM & 91.2 & 7.7 & 39.2 & - & - \\
\hline SBM & 90.7 & 6.7 & 48.5 & - & 2.3 \\
\hline Ground alfalfa & 92.2 & 9.1 & 17.9 & - & - \\
\hline RSE & 92.9 & 6.5 & 26.6 & - & 23.9 \\
\hline Pea meal & 89.6 & 4.0 & 24.3 & - & 2.1 \\
\hline Ground wheat & 89.7 & 2.9 & 14.7 & - & 2.4 \\
\hline Wheat bran & 91.5 & 7.1 & 16.7 & - & - \\
\hline Ground oats & 90.8 & 3.4 & 13.9 & - & 4.4 \\
\hline Palm kernel expeller & 92.0 & 4.6 & 16.4 & - & 9.0 \\
\hline $\mathrm{GB}+\mathrm{M}$ & 84.5 & 4.4 & 13.1 & 20.1 & 1.2 \\
\hline $\mathrm{GB}+\mathrm{SU}$ & 89.9 & 2.3 & 13.4 & 18.3 & 1.4 \\
\hline $\mathrm{GB}+\mathrm{WH}$ & 89.5 & 3.6 & 14.7 & 20.8 & 1.5 \\
\hline $\mathrm{GB}+\mathrm{SBP}$ & 89.9 & 6.9 & 13.7 & 18.0 & 1.2 \\
\hline $\mathrm{GB}+\mathrm{CNFA}$ & 90.5 & 2.6 & 13.8 & - & 12.0 \\
\hline $\mathrm{GB}+\mathrm{CNO}$ & 90.5 & 2.6 & 13.8 & - & 12.0 \\
\hline GB + RSFA & 90.5 & 2.6 & 13.8 & - & 12.0 \\
\hline $\mathrm{GB}+\mathrm{RSO}$ & 90.5 & 2.6 & 13.9 & - & 11.3 \\
\hline GB + PFA & 90.4 & 2.6 & 14.0 & - & 10.6 \\
\hline $\mathrm{GB}+\mathrm{PO}$ & 90.6 & 2.6 & 13.7 & - & 12.4 \\
\hline GB + Fat 1 & 90.4 & 2.6 & 14.0 & - & 10.5 \\
\hline GB + Fat 2 & 90.2 & 2.7 & 14.3 & - & 8.4 \\
\hline \multicolumn{6}{|l|}{ Experiments 7 to 11} \\
\hline GB (Control) & 86.7 & 2.4 & 14.5 & - & 3.0 \\
\hline HT-RSM & 89.5 & 7.5 & 38.4 & - & 3.7 \\
\hline SBM & 89.0 & 6.3 & 51.8 & - & 2.4 \\
\hline HT-RSM + RSFA & 88.8 & 2.4 & 34.2 & - & 13.3 \\
\hline $\mathrm{GB}+\mathrm{M}$ & 82.0 & 4.9 & 14.1 & 18.3 & 2.2 \\
\hline $\mathrm{GB}+\mathrm{SBP}$ & 89.0 & 6.1 & 12.6 & 18.0 & 2.4 \\
\hline $\mathrm{GB}+\mathrm{SU}$ & 88.7 & 2.2 & 12.4 & 19.1 & 2.6 \\
\hline GB + Gly & 87.2 & 2.1 & 13.0 & - & 2.7 \\
\hline GB + Fat 2 & 88.3 & 2.3 & 12.9 & - & 13.6 \\
\hline $\mathrm{GB}+\mathrm{CaF}$ & 88.3 & 4.5 & 12.9 & - & 11.9 \\
\hline GB + RSFA & 88.1 & 2.1 & 12.8 & - & 13.8 \\
\hline $\mathrm{GB}+\mathrm{PFA}$ & 89.0 & 2.4 & 12.8 & - & 12.2 \\
\hline $\mathrm{GB}+\mathrm{CNFA}$ & 85.6 & 2.5 & 12.8 & - & 8.9 \\
\hline Pellets 1 & 88.9 & 4.7 & 20.0 & - & 6.9 \\
\hline Pellets 2 & 89.3 & 4.9 & 20.1 & - & 6.7 \\
\hline Pellets 3 & 89.2 & 4.9 & 19.4 & - & 6.2 \\
\hline
\end{tabular}

${ }^{1} \mathrm{~GB}=$ Ground barley; HT-RSM = heat treated rapeseed meal ('Expro' www.karlshamns.se); RSM = rapeseed meal; $\mathrm{SBM}=$ soybean meal; RSE = rapeseed expeller; $\mathrm{M}=$ molasses $(30 \%$ of feed $) ; \mathrm{SU}=$ sugar $(13 \%$ of feed); $\mathrm{WH}=$ whey powder $(19 \%$ of feed $) ; \mathrm{SBP}=$ ground sugarbeet pulp $(65 \%$ of feed $)$; CNFA = coconut fatty acid; $\mathrm{CNO}=$ coconut oil; RSFA = rapeseed fatty acid; $\mathrm{RSO}=$ rapeseed oil; $\mathrm{PFA}=$ palm fatty acid; $\mathrm{PO}=$ palm oil; Fat 1 = fat product 'Akofeed Cattle'; Fat 2 = fat product 'Akofeed Gigant' (www.karlshamns.se) Gly = glycerol; $\mathrm{CaF}=$ calcium soapfat.

feedings in the data obtained in Exp. 1 to 6 were analyzed as Latin square with 5 treatments (feeds), 5 periods (days), and 2 blocks with 5 animals in each block, using the design number 10 described by Patterson and Lucas (1962). Least squares means were used in the statistical analysis of differences between means.

The statistical analysis was performed using the GLM procedure of SAS (version 6.12, SAS Institute, 1989). Carryover effects were not significant and were thus removed from the model. An interaction between the effects of treatment and period was observed in Exp. 4 but in the remaining Exp. (1, 2, 3, 5, and 6) the effect of interaction was removed from the model.

In Exp. 7 to 11, a Latin square design with 2 blocks of 6 animals with 6 periods (days), and 6 treatments (combinations) was used to obtain a balanced design and to minimize carryover effects. The statistical calculation of the number of times the animals chose one feed as a winner over the other was performed using the binomial distribution for each paired analysis and the $\chi^{2}$ distribution for analysis of differences between the total number of choices for the 4 feeds in each experiment. The results were registered as "no preference" when the winning feed differed in the morning and afternoon and these were removed from the observations in the binomial and $\chi^{2}$ analysis.

\section{RESULTS}

\section{Experiments 1 to 6: Eating Rate}

The results of Exp. 1 to 6 are presented in Tables 6 and 7. During the first 5 successive experiments, the eating rate of the GB control feed increased from 147 to $179 \mathrm{~g} / \mathrm{min}$ (first $3 \mathrm{~min}$ ). Changes in eating rate for barley were not so large or consistent over time when considering the mean rate for the entire 10 min meal. In Exp. 1, the 2 rapeseed meal products had a large particle size and the eating rate was significantly higher compared with the other feeds. In Exp. 6, when HT-RSM was compared after being ground in a hammer mill, eating rate of HT-RSM during the first $3 \mathrm{~min}$ of the meal was considerably lower but still significantly higher than that of the other feeds, with the exception of the barley control feed. The effect of particle size on eating rate in Exp. 1 is illustrated in Figure 1 ; the regression between particle size and eating rate was significant $(P<0.05)$ with a coefficient of determination ( $\mathrm{R}^{2}$ value) of 0.9. In Exp. 6, where the particle size of the feeds did not differ as much, the regression had a low coefficient of determination $\left(\mathrm{R}^{2}=0.3\right)$ and there was no significant effect of particle size on eating rate. In Exp. 6, both RSE and pea meal had a significantly lower eating rate compared with HT-RSM but were comparable to soybean meal (SBM) with regard to eating rate and leftovers.

In Exp. 6, a significant interaction between treatment (feed) and period (day) was obtained initially. This was due to a lack of appetite at morning feeding for 1 of the 2 heifers that were given GB (control feed) on $\mathrm{d} 5$. This heifer consumed almost no barley in the morning (140 g) with resulting low barley eating rate (14 g/min). However, in the afternoon the animal consumed all the barley (993 g) and achieved a barley 
Table 5. Content of fatty acids and the proportion of FFA in the fat-based additives in Experiments 4, 5, and $9^{1}$

\begin{tabular}{lcccccccccr}
\hline & \multicolumn{10}{c}{ Fatty acids, \% } \\
\cline { 2 - 11 } & \multicolumn{1}{c}{ CC12 } & C12:0 & C14:0 & C16:0 & C18:0 & C18:1 & C18:2 & C18:3 & Other & FFA \\
\hline CNFA & 12.4 & 42.8 & 18.3 & 11.0 & 3.8 & 9.5 & 2.2 & 0 & 0 & 93.9 \\
CNO & 13.3 & 46.4 & 18.5 & 9.4 & 3.0 & 7.2 & 1.9 & 0 & 0.3 & 0.2 \\
RSFA & 0.2 & 0.7 & 0.4 & 6.7 & 2.9 & 56.8 & 20.7 & 7.8 & 3.8 & 79.2 \\
RSO & 0 & 0 & 0.2 & 4.4 & 63.4 & 18.4 & 10.4 & 0 & 3.2 & 1.1 \\
PFA & 0 & 0.3 & 1 & 47.0 & 4.6 & 37.8 & 7.8 & 0 & 1.5 & 88.7 \\
PO & 0 & 0.2 & 1 & 43.3 & 44.6 & 9.4 & 0.3 & 0 & 1.2 & 0.8 \\
Fat 1 & 0.5 & 1.6 & 1.6 & 44.2 & 6.6 & 36.1 & 7.7 & 0.3 & 1.4 & 71.3 \\
Fat 2 (Exp. 5) & 0.4 & 0.2 & 1.6 & 66.9 & 20.0 & 8.7 & 0.2 & 0 & 2.0 & 98.0 \\
Fat 2 (Exp. 9) & 0 & 0.9 & 3.6 & 78.0 & 2.4 & 11.6 & 2.4 & 0 & 1.1 & 97.7 \\
Calcium soapfat & 0 & 0.2 & 1.0 & 45.2 & 4.3 & 38.7 & 8.7 & 0 & 1.9 & 88.4 \\
\hline
\end{tabular}

${ }^{1} \mathrm{CNFA}=$ Coconut fatty acid; $\mathrm{CNO}=$ coconut oil; $\mathrm{RSFA}=$ rapeseed fatty acid; $\mathrm{RSO}=$ rapeseed oil; $\mathrm{PFA}=$ palm fatty acid; $\mathrm{PO}=$ palm oil: Fat 1 = fat product 'Akofeed Cattle'; Fat 2 = fat product 'Akofeed Gigant' (www.karlshamns.se).

eating rate that was in the range of that normally observed for the barley control feed (114 g/min), showing that the lack of appetite in the morning was not due to low palatability but probably some temporary disturbance. The interaction was no longer significant when the observation was removed from the data set. The least squares means obtained from this analysis are presented in Table 6 .

The palm kernel expeller meal particle size was much larger than that for the other feeds in Exp. 2 but eating rate for palm kernel expeller was significantly lower and amounts of leftover feed was higher. No significant differences were found when eating rate was compared among the different cereal products based on wheat, oats, and barley. Wet molasses mixed with the barley $(\mathbf{G B}+\mathbf{M})$ resulted in a larger particle size compared with the other feeds in Exp. 3. The $\mathrm{GB}+\mathrm{M}$ mixture was the only sweet additive that produced a significantly higher eating rate than the GB control feed. The GB + whey mixture had a significantly lower eating rate compared with the barley with sugar feed, and the amount of feed leftover was significantly higher.

In Exp. 4 and 5 with the additives of fat and fat byproducts (see Table 6 ), the eating rate for the GB + rapeseed fatty acid (RSFA) and the barley with palm oil was significantly higher than the other fat additives. The 2 mixtures with fat additives based on coconut (i.e., barley with CNFA and barley with coconut oil) had lower eating rates and large amounts of leftover feed. In Exp. 4 an interaction between treatment and period was obtained; the least squares means for each feed and $d$ are presented in Table 7. Although a certain variation between days was observed, the overall picture of high eating rate and low levels of leftovers for mixtures with products based on rapeseed was still the same as the mean results presented in
Table 6 . The data presented in Table 7 revealed a large variation in the acceptance of the GB+CNFA with an eating rate ranging from 23 to $183 \mathrm{~g} / \mathrm{min}$.

\section{Experiments 7 to 11: Preference}

The results of the preference tests in Exp. 7 to 11 are presented in Table 8 . The results showed significant differences only in a few cases. In Exp. 7, a significantly higher number of heifers preferred the plain HT-RSM to the HT-RSM with RSFA. The animals chose the plain HT-RSM 3 times more often than the RSFA but the differences between the feeds in the total number of choices was not significant. However, in Exp. 10, GB+RSFA was chosen significantly more often than GB+CNFA, which created a significant difference with the GB+RSFA as the "winner". A significant difference between feeds in the total number of choices was observed in Exp. 9 where the GB mixture with glycerol was preferred about 2-fold more often as the other additives. In Exp. 11, no differences between the 3 pellets were observed, but a clear preference for pellets compared with GB was demonstrated. In Exp. 8 no differences were observed between the sweet additive combinations.

\section{DISCUSSION}

Palatability is a controversial term and it has been argued that the term should not be used because of the limited possibilities to define the exact nature of palatability (Ramirez, 1990). Kissileff (1990) suggested the use of 2 concepts: "intrinsic palatability," which refers to the characteristics of a feed, and "learned palatability," which refers to the response that is based on an animal's earlier acquired feed experiences. The use of heifers with limited experience in 
Table 6. Eating rate, amounts of feed not consumed, and mean particle size of feed (Experiments 1 to 6$)^{1,2}$

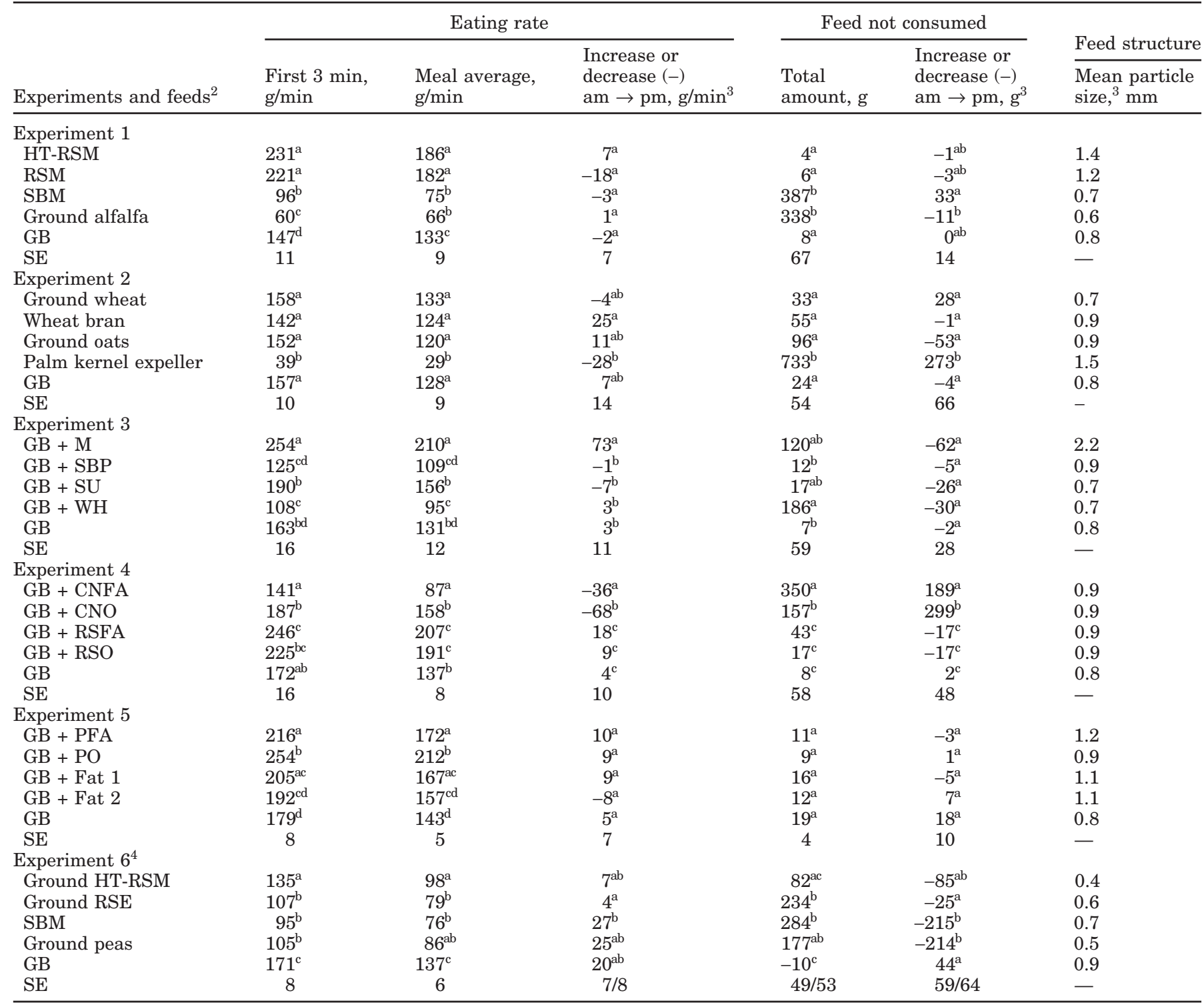

${ }^{a-d}$ Means within the same experiment in the same column with different superscripts differ $(P \leq 0.05)$.

${ }^{1}$ Eating rate determined during the intake of $1 \mathrm{~kg}$ feed components; the total amount of feed not consumed within 10 min was evaluated. Values represent least square means. Ground barley was used as control feed in all the experiments and as a base in mixtures with additives.

${ }^{2} \mathrm{HT}-\mathrm{RSM}=$ Heat-treated rapeseed meal 'Expro' (www.karlshamns.se); RSM = rapeseed meal, $\mathrm{SBM}=$ soybean meal; GB = ground barley; $\mathrm{M}=$ molasses $(30 \%$ of feed); SBP = sugarbeet pulp (65\% of feed); SU = sugar (13\% of feed); WH = whey powder $(19 \%$ of feed 0$)$; CNFA = coconut fatty acid; $\mathrm{CNO}=$ coconut oil; RSFA = rapeseed fatty acid; $\mathrm{RSO}=$ rapeseed oil; $\mathrm{PFA}=$ palm fatty acid; $\mathrm{PO}=$ palm oil; Fat $1=$ fat product 'Akofeed Cattle'; Fat 2 = fat product 'Akofeed Gigant' (www.karlshamns.se); RSE = rapeseed expeller.

${ }^{3}$ The increase or decrease (-) in eating rate and in amount of feed not consumed from morning to afternoon feeding and mean particle size of feed.

${ }^{4}$ Data from feed GB has 1 observation missing (1 animal last period).

concentrate feeding in the experiments presented here was an attempt to decrease the effects of earlier experiences on animal response to the different concentrate components tested. Several researchers mention that the effects of learning and earlier feed experience can influence responses (Forbes and Kyriazakis, 1995; Ar- ave, 1997). In this study the barley control feed reappeared throughout the experiment and it is possible that the heifers' response to the GB was affected by that circumstance. The increase over Exp. 1 to 5 in the eating rate (during the first $3 \mathrm{~min}$ of the meal) was an indication of this effect. However, preference for 
Table 7. Eating rate during the intake of $1 \mathrm{~kg}$ of feed components on different $\mathrm{d}$ in Experiment $4^{1,2}$

\begin{tabular}{|c|c|c|c|c|c|c|}
\hline \multirow[b]{2}{*}{ Period (d) } & \multicolumn{5}{|c|}{ Feed component } & \multirow[b]{2}{*}{$\mathrm{SE}$} \\
\hline & $\mathrm{GB}+\mathrm{CNFA}$ & $\mathrm{GB}+\mathrm{CNO}$ & GB + RSFA & $\mathrm{GB}+\mathrm{RSO}$ & GB & \\
\hline 1 & $23^{\mathrm{a}}$ & $120^{\mathrm{b}}$ & $216^{\mathrm{c}}$ & $212^{\mathrm{c}}$ & $142^{\mathrm{b}}$ & 21 \\
\hline 2 & $69^{\mathrm{a}}$ & $107^{\text {abd }}$ & $210^{\mathrm{c}}$ & $165^{\mathrm{cd}}$ & $142^{\mathrm{bd}}$ & - \\
\hline 3 & $58^{\mathrm{a}}$ & $171^{\mathrm{b}}$ & $146^{\mathrm{b}}$ & $197^{\mathrm{b}}$ & $134^{\mathrm{b}}$ & - \\
\hline 4 & $183^{\mathrm{ab}}$ & $181^{\mathrm{b}}$ & $248^{\mathrm{a}}$ & $197^{\mathrm{ab}}$ & $142^{\mathrm{b}}$ & - \\
\hline 5 & $102^{\mathrm{a}}$ & $210^{\mathrm{b}}$ & $216^{\mathrm{b}}$ & $184^{\mathrm{bc}}$ & $126^{\mathrm{ac}}$ & - \\
\hline
\end{tabular}

barley did not increase over time (from Exp. 7 to Exp. 11), and therefore the effect of repeating the GB control feed may not have been as great as first suspected. A significantly higher eating rate was obtained for the barley control compared with SBM, ground alfalfa, palm kernel expeller, RSE, and ground peas. This is in agreement with the results of Klopfer et al. (1981) who found that crushed barley was the preferred feed compared with the other 20 feeds in the study.

The eating rate during the first 3 min of the meal is a measurement independent of the observer's judgment of when the meal has been completed and therefore perhaps gives the best comparison between feeds. However, with only a few exceptions (alfalfa and $\mathrm{GB}+\mathrm{CNFA}$ ), the relationship between the eating rate during the first $3 \mathrm{~min}$ and the entire meal was similar for the different feeds, which showed that the eating rate for the entire meal could be used to compare eating rate for the different feeds if the same person acts as an observer throughout the experiment.

The results of Exp. 1 and 6 showed that the HTRSM was eaten at a significantly higher rate compared with the other feeds with the exception of GB. The comparatively high amounts of SBM leftovers in Exp. 1 and 6 contributed to the lower eating rate and were

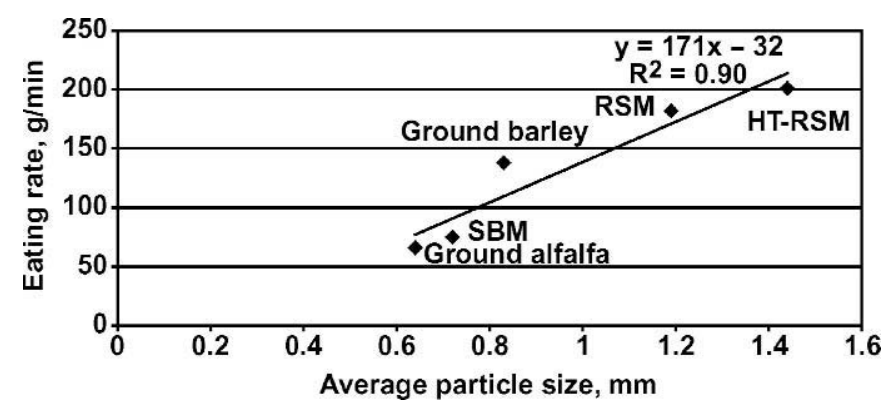

Figure 1. Regression between particle sizes and eating rate for feed components in Experiment $1(P<0.05)$. HT-RSM $=$ heat-treated rapeseed meal; $\mathrm{RSM}=$ rapeseed meal; $\mathrm{SBM}=$ soybean meal. an indication of a lower palatability for SBM compared with HT-RSM. In Exp. 7, heifers had the opportunity to choose the preferred feed and the HT-RSM had the highest number of preferences, which was only significant when compared with the HT-RSM with the RSFA additive. In this case, the preference test did not confirm the indication of a lower palatability for SBM compared with HT-RSM that was observed in Exp. 1 and 6. In contrast to Exp. 7, Bertilsson et al. (1994) observed a preference for HT-RSM over SBM and RSE in a preference experiment with 4 supplements (HT-RSM, SBM, RSE, and linseed expeller). In a number of long-term experiments, Emanuelson (1989) also concluded that that the possibility of palatability complications with rapeseed from double-low cultivars were small and that no negative effect on feed intake could be observed when feeding up to 2.5 $\mathrm{kg}$ of DM rapeseed products. As in the present experiment, all rapeseed products used in the experiments of Bertilsson et al. (1994) and Emanuelson (1989) were of the "double-low" type. In experiments with rapeseed products containing higher levels of glucosinolates, a linear decrease in supplement intake and a lower intake was obtained with rapeseed products compared with SBM (Lardy and Kerley, 1994).

In Exp. 2, the large quantity of leftover palm kernel expeller indicated that the heifers were unwilling to consume the feed. The increase in the amount left over at the afternoon feeding compared with the morning feeding also indicated that the animals had not appreciated the first experience of the feed. As the objective of the project was to find feed ingredients with a high palatability, the palm kernel expeller was excluded from Exp. 7 to 11. The similar eating rate obtained for all the cereal products in Exp. 2 showed that the results obtained for control feed barley may also be representative for ground oats, wheat bran, and wheat.

The higher eating rate for the $\mathrm{GB}+\mathrm{M}$ compared with the other feeds in Exp. 3 could be due to the effect of 
Table 8. The number of times each feed was preferred in Experiments 7 to $11^{1,2}$

\begin{tabular}{|c|c|c|c|c|c|c|c|}
\hline & \multicolumn{6}{|c|}{ Feed combinations } & \multirow[b]{2}{*}{ Total } \\
\hline & 1 and 2 & 1 and 3 & 1 and 4 & 2 and 3 & 2 and 4 & 3 and 4 & \\
\hline \multicolumn{8}{|l|}{ Experiment 7} \\
\hline HT-RSM & 5 & 8 & 5 & - & - & - & 18 \\
\hline SBM & 4 & - & - & 6 & 4 & - & 14 \\
\hline HT-RSM + RSFA & - & 1 & - & 1 & - & 4 & 6 \\
\hline GB & - & - & 4 & - & 3 & 4 & 11 \\
\hline No preference ${ }^{3}$ & 3 & 3 & 3 & 5 & 5 & 4 & 23 \\
\hline Significance $^{4}$ & NS & $*$ & NS & NS & NS & NS & NS \\
\hline \multicolumn{8}{|l|}{ Experiment 8} \\
\hline $\mathrm{GB}+\mathrm{M}$ & 2 & 6 & 5 & - & - & - & 13 \\
\hline $\mathrm{GB}+\mathrm{SBP}$ & 5 & - & - & 6 & 2 & - & 13 \\
\hline $\mathrm{GB}+\mathrm{SU}$ & - & 3 & - & 1 & - & - & 4 \\
\hline GB & - & - & 5 & - & 1 & 3 & 9 \\
\hline No preference ${ }^{3}$ & 5 & 3 & 2 & 5 & 9 & 9 & 33 \\
\hline Significance $^{4}$ & NS & NS & NS & NS & NS & NS & NS \\
\hline \multicolumn{8}{|l|}{ Experiment 9} \\
\hline $\mathrm{GB}+\mathrm{RSFA}$ & 5 & 8 & 4 & - & - & - & 17 \\
\hline $\mathrm{GB}+\mathrm{PFA}$ & 3 & - & - & 5 & 4 & - & 12 \\
\hline $\mathrm{GB}+\mathrm{CNFA}$ & - & 1 & - & 3 & - & - & 4 \\
\hline GB & - & - & 1 & - & 3 & 7 & 11 \\
\hline No preference ${ }^{3}$ & 4 & 3 & 7 & 4 & 5 & 5 & 28 \\
\hline Significance ${ }^{4}$ & NS & * & NS & NS & NS & NS & $*$ \\
\hline \multicolumn{8}{|l|}{ Experiment 10} \\
\hline GB + Gly & 4 & 5 & 6 & - & - & - & 15 \\
\hline $\mathrm{GB}+$ Fat 2 & 2 & - & - & 2 & 3 & - & 7 \\
\hline $\mathrm{GB}+\mathrm{CaF}$ & - & 2 & - & 1 & - & 4 & 7 \\
\hline GB & - & - & 1 & - & 2 & 1 & 4 \\
\hline No preference ${ }^{3}$ & 6 & 5 & 5 & 9 & 7 & 7 & 39 \\
\hline Significance $^{4}$ & NS & NS & NS & NS & NS & NS & $*$ \\
\hline \multicolumn{8}{|l|}{ Experiment 11} \\
\hline Pellets 1 & 2 & 1 & 11 & - & - & - & 14 \\
\hline Pellets 2 & 3 & - & - & 2 & 11 & - & 16 \\
\hline Pellets 3 & - & 3 & - & 2 & - & 10 & 15 \\
\hline GB & - & - & - & - & - & - & - \\
\hline No preference ${ }^{3}$ & 7 & 8 & 1 & 8 & 1 & 2 & 27 \\
\hline Significance $^{4}$ & $\mathrm{NS}$ & NS & $* *$ & NS & $* *$ & $* *$ & $*$ \\
\hline
\end{tabular}

\footnotetext{
${ }^{1}$ Experiments tested feed preference of 12 heifers offered a choice of 2 feeds at each feeding occasion. Feeds ( 1 to 4 ) were offered in 6 different combinations ( 1 and 2, 1 and 3,1 and 4,2 and 3,2 and 4, 3 and 4). Ground barley was used as control feed and in mixtures with additives (Experiments 8 to 10). Binomial distribution was used for significance test of difference for each combination of 2 feeds, and $\chi^{2}$ for the difference in total number of times a feed was preferred.

${ }^{2}$ HT-RSM = Heat-treated rapeseed meal 'Expro' (www.karlshamns.se); SBM = soybean meal; RSFA = rapeseed fatty acid; $\mathrm{GB}$ = ground barley; $\mathrm{M}$ = molasses; $\mathrm{SBP}$ = ground sugarbeet pulp; $\mathrm{SU}=$ sugar; $\mathrm{PFA}=$ palm fatty acid; CNFA = coconut fatty acid; Gly = glycerol; Fat 2 = 'Akofeed Gigant' (www.karlshamns.se); $\mathrm{CaF}=$ calcium soapfat.

${ }^{3}$ Number of heifers with opposite choices at morning and afternoon feeding.

${ }^{4} \mathrm{NS}=$ not significant; $*=P \leq 0.05 ; * *=P \leq 0.01$.
}

a larger particle size, the effect of high palatability, or a combination of these factors. With the exception of $\mathrm{GB}+\mathrm{M}$ with its larger particle size, none of the sweet additives in Exp. 3 caused a significantly higher eating rate compared with the barley control feed, and no significant differences in preference were obtained between the sweet additives studied in Exp. 8. This indicates that the sweet additives did not increase palatability. One reason for this could be the high sugar content in the mixtures-more than 15 to $20 \%$ of DM. It is possible that the concentration of the sweet additives was too high. In a review article about taste,
Goatcher and Church (1970a) mention that cattle are sensitive to high concentrations of bitter, salt, sour, and sweet additives. Although it has been shown by Chiy and Phillips (1999) that sweet concentrates, with a similar content of water-soluble carbohydrates (198 $\mathrm{g} / \mathrm{kg}$ of DM) as in the present experiment, were consumed faster than salty and bitter concentrates, that experiment did not include concentrates without any additive. In an experiment in which cattle, sheep, and goats were offered water with increasing contents of sucrose, cattle demonstrated an increased preference up to $10 \%$ sucrose concentration, but at higher concen- 
trations they showed a reaction of mild rejection (Goatcher and Church, 1970b). A clear preference for diets sweetened with sucrose (1.5\% of dietary DM) was observed by Nombekela et al. (1994) in an experiment where early-lactation cows were fed TMR diets. However, several other experiments with TMR with similar concentrations of sweet supplements have failed to give responses in DM intakes or in milk production parameters (Nombekela and Murphy, 1995; Murphy et al., 1997). Although additives to a TMR feed are difficult to compare with the additives to the small concentrate rations used in the present experiments, it seems doubtful that lower concentrations of sweet additives would give a clear response in preference. The outcome of an experiment with paired comparisons of 20 different feeds on 2 Jersey cows (Klopfer et al., 1981) showed that blocks of molasses had a low ranking along with saltblocks and thypha silage, whereas barley, dairy meal, corn silage, hay, pasture (fresh and frozen), and esparsett were highly ranked by the animals. The low ranking of the molasses block and the high ranking of the barley and dairy meal in the experiment by Klopfer et al. (1981) and the lack of response to molasses flavor in the experiment by Nombekela et al. (1994) are more indications that the addition of molasses in most cases will not improve palatability to a cereal product such as barley.

Fat and fatty acid additives in cattle diets can lower both DMI and DM digestibility of the diet so that including fat in the diet does not always lead to an increase in net energy intake, even though the energy density of the diet is increased (Allen, 2000). Analyzing a large number of experiments, Allen (2000) found large differences between different fat sources and decreases in DMI that often occurred with increasing levels of fat in the diet, in particular for calcium salts of PFA. In the present experiments, the addition of $10 \%$ of fat products to the concentrate ration gave a fat content in the total diet of approximately $3 \%$; this level of fat inclusion in the diet is generally consumed without any major effects on DMI or digestibility and is well below the maximum $5 \%$ recommended for dairy cows in the Swedish feed tables for ruminants (Spörndly, 2003).

Experiment 4 showed that GB mixed with $10 \%$ RSFA or rapeseed oil was consumed with a high eating rate whereas eating rate was generally lower and leftovers higher when the heifers were given the mixtures with CNFA and coconut oil. Eating rate for the mixture with palm oil in Exp. 5 was comparable with the eating rate for the mixture with RSFA and the eating rate for the mixture with PFA was slightly lower. Some of these results were confirmed in Exp. 10 where the barley mixed with RSFA received the highest number of preferences whereas the mixture with CNFA had the lowest number of choices. No significant difference was observed in the eating rate between the mixtures with fatty acids and oil of the rapeseed additives, whereas a higher eating rate for the coconut and palm oil compared with the coconut and palm fatty acid, respectively, was observed. In general, the oil and fatty acid additives seem to have been well accepted by the animals. It is possible that higher levels of fat in the fatty acid inclusion would have decreased the acceptability. In an experiment in which grazing cows were offered $1 \mathrm{~kg}$ of rolled oats twice daily with increasing levels (0 to 40\%) of fatty acids (mainly C16:0 and C18:0), the acceptability of the supplement decreased rapidly at fatty acid concentrations above $20 \%$ (King et al., 1990).

In Exp. 10 the preference test showed an overall difference between feeds. The GB had a low total number of preferred choices; the highest number of total choices was observed for the GB mixed with $10 \%$ glycerol. This indicates that the heifers preferred the mixture with glycerol. There has been an interest in supplementation of dairy cows with glycerol as an alternative to propylene glycol to alleviate ketosis (Fisher et al., 1971, 1973; Khalili et al., 1997). In a recent study it has been shown that glycerol supplements resulted in $17 \%$ lower DMI when fed to prepartum cows (DeFrain et al., 2004), whereas earlier results from other experiments showed that glycerol, fed at a similar supplementary level $(0.47 \mathrm{~kg} / \mathrm{d})$, had a favorable effect on cow appetite (Fisher et al., 1971). However, the levels of glycerol supplementation in the present experiment were considerably lower $(0.1 \mathrm{~kg} / \mathrm{d})$ compared with the levels fed in most of the previous experiments, and it seems unlikely that any negative effects would be observed at these levels of glycerol feeding. The calcium soap fat and the commercial fat $2 \mathrm{had}$ an intermediate number of preferred choices. Previous studies comparing different fat additives have demonstrated a decrease in DMI when calcium salts of PFA have been fed (Grummer et al., 1990; Allen, 2000). However, in the experiment presented by Grummer et al. (1990), no differences in intake between different fat supplements were observed when the supplements were offered as part of a grain mix. Grummer et al. (1990) concluded that differences in acceptability between the fat supplements studied were probably masked when they were mixed with grain. The data obtained in Exp. 10 support the conclusion that supplements with calcium salts of fatty acids mixed with grain are well accepted by cattle. However, in the earlier mentioned analysis that included many experiments (Allen, 2000), cattle showed a clear decrease in DMI as the concentration of calcium salts of PFA increased in the 
TMR mixture. Thus, it is possible that the decrease in DMI observed was mainly a metabolic effect rather than an effect of acceptability, but more experimental data is needed to examine this further.

In Exp. 11 the animals always preferred the concentrate pellets to the GB, but no differences between the 3 types of concentrate pellets were observed. A preference for pellets over ground meal was also observed by Arave et al. (1983) who also found that rolled barley was preferred over pellets. The results of Exp. 11 clearly illustrate the large effects that the feed structure can have on cattle preference. The results also show that the heifers did not discriminate between pelleted concentrates with a similar cereal content where soybean components were replaced with HT-RSM and dried draff or with rapeseed products and pea meal.

An interesting observation was that feeds producing a high eating rate in Exp. 1 to 6 were often among the feeds that were chosen most often in the preference trials 7 to 11 , thus indicating that eating rate can be used as an indirect measure of preference if the structures of the studied feeds are comparable. However, the short-term feeding of each feed component can only give indications of which feed components might potentially function as stimuli for cow motivation.

\section{CONCLUSIONS}

The results from the 11 short-term experiments in which 29 different feeds or combination of feeds were studied to investigate eating rate, feed choice, or both showed that it was difficult to find feeds that could clearly be defined as the more preferred by the heifers. However, a number of feeds can be classified as being among the most preferred feeds: pelleted feeds, HTRSM, barley with $10 \%$ RSFA, barley with $10 \%$ palm oil, and barley with $10 \%$ glycerol. Of all the feeds tested in Exp. 1 to 6, ground palm kernel expeller gave the lowest eating rate and the highest amount of feed leftovers, leading to the conclusion that heifers indicated distaste for this feed. A clear preference for pellets over GB was demonstrated but no difference in preference was observed for pellets of different compositions. The lack of a definitive highly preferred feed and no concrete demonstration of preference between different pelleted concentrates leads to the conclusion that it may be difficult to compose a feed for cattle from the feed components tested in these experiments that will be more desirable than conventional pelleted concentrates.

\section{ACKNOWLEDGMENTS}

These experiments were financed by the Swedish Farmer's Foundation for Agricultural Research, the European Union, and the commercial companies AarhusKarlshamns, Danisco, and Svenska Foder. These contributions are all gratefully acknowledged.

\section{REFERENCES}

Allen, M. S. 2000. Effects of diet on short-term regulation of feed intake by lactating dairy cattle. J. Dairy Sci. 83:1598-1624.

Andersson, R., and B. Hedlund. 1983. HPLC analysis of organic acids in lactic acid fermented vegetables. Z. Lebensm. Unters. Forsch. 176:440-443.

Arave, C. W. 1997. Assessing sensory capacity of animals using operant technology. J. Anim. Sci. 74:1996-2009.

Arave, C. W., W. Temple, R. Kilgour, L. R. Matthews, and J. L. Walters. 1983. Effect of heifer feeding preference of adding flavor or pelleting a dairy meal. J. Dairy Sci. 66:107-112.

Bertilsson, J., M. Emanuelson, and M. Murphy. 1994. Linseed products for dairy cows. Report 229, Dept. Anim. Nutr. Management, Swedish Univ. Agric. Sci., Uppsala, Sweden. [In Swedish with English summary]

Chiy, P. C., and C. J. C. Phillips. 1999. The rate of intake of sweet, salty and bitter concentrates by dairy cows. Anim. Sci. 68:731740.

DeFrain, J. M., A. R. Hippen, K. F. Kalscheur, and P. W. Jardon. 2004. Feeding glycerol to transition dairy cows: Effects on blood metabolites and lactation performance. J. Dairy Sci. 87:41954206.

Emanuelson, M. 1989. Rapeseed products of double low cultivars to dairy cows. Effects of long term feeding and studies on rumen metabolism. PhD Thesis, Report 189, Dept. Anim. Nutr. Management, Swedish Univ. Agric. Sci., Uppsala, Sweden.

European Union. 1984. Determination of crude and fats. Off. J. L. 15:29-30.

Fisher, L. J., J. D. Erfle, G. A. Lodge, and F. D. Sauer. 1973. Effects of propylene glycol or glycerol supplementation of the diet of dairy cows on feed intake, milk yield and composition, and incidence of ketosis. Can. J. Anim. Sci. 53:289-296.

Fisher, L. J., J. D. Erfle, and F. D. Sauer. 1971. Preliminary evaluation of the addition of glycogenic materials to the rations of lactating cows. Can. J. Anim. Sci. 51:721-727.

Forbes, J. M., and I. Kyriazakis. 1995. Food preferences in farm animals: Why don't they always choose wisely? Proc. Nutr. Soc. 54:429-440.

Goatcher, W. D., and D. C. Church. 1970a. Review of some nutritional aspects of the sense of taste. J. Anim. Sci. 31:973-981.

Goatcher, W. D., and D. C. Church. 1970b. Taste responses in ruminants. III. Reactions of pygmy goats, normal goats, sheep and cattle to sucrose and sodium chloride. J. Anim. Sci. 31:364-372.

Goering, H. K., and P. J. Van Soest. 1970. Forage Fiber Analyses (Apparatus, Reagents, Procedures, and Some Applications). Agric. Handbook No. 379. ARS-USDA, Washington, DC.

Grummer, R. R., M. L. Hatfield, and M. R. Dentine. 1990. Acceptability of fat supplements in four dairy herds. J. Dairy Sci. 73:852-857.

International Union of Pure and Applied Chemistry (IUPAC). 1992. Standard methods for the analysis of oils, fats and derivatives (2.302). 7th revised and enlarged edition; 1st supplement to the 7th edition. IUPAC, Research Triangle Park, NC.

Khalili, H., T. Varvikko, V. Toivonen, K. Hissa, and M. Suvitie. 1997. The effects of added glycerol or unprotected free fatty acids or a combination of the two on silage intake, milk production, rumen fermentation and diet digestibility in cows given grass silage based diets. Agric. Food Sci. Finland 6:349-362.

King, K. R., C. R. Stockdale, and T. E. Trigg. 1990. Acceptability of high fat grain mixtures offered to grazing dairy cows. Aust. J. Exp. Agric. 30:595-597. 
Kissileff, H. R. 1990. Some suggestions on dealing with palatabilityresponse to Ramirez. Appetite 14:162-166.

Klopfer, F. D., R. Kilgour, and L. R. Matthews. 1981. Paired comparison analysis of palatabilities of twenty foods to dairy cows. Proc. N. Z. Soc. Anim. Prod. 41:242-247.

Lardy, G. P., and M. S. Kerley. 1994. Effect of increasing the dietary level of rapeseed meal on intake by growing beef steers. J. Anim. Sci. 72:1936-1942.

Larsson, K., and S. Bengtsson. 1983. Determination of non-structural carbohydrates in plant material. Method description no. 22, National Laboratory for Agricultural Chemistry, Uppsala, Sweden. [In Swedish]

Lindgren, E. 1979. Nutrient content in roughages determined in vitro and with different laboratory methods. Report 45, Dept. Anim. Nutr. Management, Swedish Univ. Agric. Sci., Uppsala, Sweden. [In Swedish]

Melin, M., H. Wiktorsson, and L. Norell. 2005. Analysis of feeding and drinking patterns of dairy cows in two cow traffic situations in automatic milking systems. J. Dairy Sci. 88:71-85.

Murphy, M. R., A. W. P. Geijesl, E. C. Hall, and R. D. Shanks. 1997. Dietary variety via sweetening and voluntary feed intake of lactating dairy cows. J. Dairy Sci. 80:894-897.

Nombekela, S. W., and M. R. Murphy. 1995. Sucrose supplementation and feed intake of dairy cows in early lactation. J. Dairy Sci. 78:880-885.

Nombekela, S. W., M. R. Murphy, H. W. Gonyou, and J. I. Marden. 1994. Dietary preferences in early lactation cows as affected by primary tastes and some common feed flavors. J. Dairy Sci. 77:2393-2399.
Nordic Committee on Food Analysis. 1976. Nitrogen. Determination in food and feed according to Kjeldahl. No. 6. 3rd ed. Esbo, Finland.

Patterson, H. D., and H. L. Lucas. 1962. Change-over designs. N. Carolina Agric. Exp. Stn., USDA and the United States Department of Agriculture. Tech. Bull. 147. North Carolina State Univ., Raleigh.

Ramirez, I. 1990. What do we mean when we say "Palatable food?" Appetite 14:159-161.

Rodenburg, J., E. Focker, and K. Hand. 2004. Effect of the composition of concentrate fed in the milking box, on milking frequency and voluntary attendance in automatic milking systems. In: Automatic Milking - A Better Understanding. A. Meijering, H. Hogeveen, and C. J. A. M. de Koning ed. Proc. Symp. Automatic Milking, Lelystad, The Netherlands. Wageningen Academic Publishers, Wageningen, The Netherlands.

SAS Institute. 1989. SAS User's Guide Statistics. Version 6.12. SAS Inst., Inc., Cary, NC

Spörndly, R., ed. 2003. Feed tables for ruminants 2003. Report 257, Dept. of Anim. Nutr. and Management, Swedish Univ. of Agric. Sci., Uppsala, Sweden. [In Swedish]

Spörndly, E., and E. Wredle. 2004. Automatic milking and grazing Effects of distance to pasture and level of supplements on milk yield and cow behavior. J. Dairy Sci. 87:1702-1712.

van Dooren, H. J. C., E. Spörndly, and H. Wiktorsson. 2002. Automatic milking and grazing. Applied grazing strategies. Deliverable D25, EU project "Implications of the introduction of automatic milking on dairy farms" (QLK5-2000-31006): http://www.automaticmilking.nl Accessed May 10, 2005. 